\title{
Measurement of Moisture Conductivity of Clothing
}

\author{
Satoru TAKADA ${ }^{1)}$, Shuichi HoKOI ${ }^{1)}$ and Kazuhiro NAKAZAWA ${ }^{2)}$ \\ ${ }^{1)}$ Graduate School of Engineering, Kyoto University \\ Yoshidahonmachi Sakyo-ku Kyoto 606-8501, Japan \\ Tel. +8175753 5779 Fax. +8175753 5779 \\ E-mail: satoruta@archi.kyoto-u.ac.jp, hokoi@archi.kyoto-u.ac.jp \\ ${ }^{2)}$ Kansai Electric Power Company, Inc. \\ 3-3-22 Nakanoshima Kita-ku Osaka 530-8270 Japan \\ E-mail: K477215@kepco.co.jp
}

(received on November 18, 2003, accepted on December 24, 2003)

\begin{abstract}
In this paper a method to measure the moisture (water vapor) conductivity of clothing is proposed. The method is based on the wet cup method, which is often used for building materials. The proposed method overcomes the difficulty of applying the wet cup method to thin and air-permeable material like cloth by determining the surface moisture transfer resistances at both sides of cloth gravimetrically. Measured results on cotton cloth are shown.
\end{abstract}

Key words: moisture conductivity, clothing, wet cup method, moisture transfer at surface, thermal comfort.

\section{Introduction}

The evaporation of sweat through clothing and from clothing influences the temperature regulation system and the thermal sensation of the human body. Therefore, in planning thermal environments, it is important to understand the characteristics of moisture accumulation and transfer in and around clothing. In analyzing the transfer of heat and moisture around the human body, one of the most important physical properties is the moisture conductivity of cloth.

Figures 1 and 2 are the result of the sensitivity analysis of moisture (water vapor) conductivity in calculating heat and moisture transfer in clothing and the human body (Takada et al., 2001). The figures show the temperatures of clothing and skin during two hours of thermal transient including a stay in a high temperature environment that causes sweating. (The calculation uses the two-node model for the human body's temperature regulation system and the simultaneous heat and moisture transfer model for clothing.) The results of numerical analysis are shown with the results of the experiment. The differences in the values of moisture conductivity of clothing have a significant influence not only on the temperature of the clothing but also on the temperature of the skin. Thus the moisture conductivity of clothing has a significant affect on the transfer of heat and moisture around the human body in a non-steady state.

Moisture conductivity also plays an important role in the analysis of heat and moisture transfer in porous building materials. Usually the cup method (ISO $12572,2000)$ is used. In many cases, the specimen is cut out thick enough for the moisture transfer resistance at the surface of the material to be far smaller than that of the specimen itself. Therefore surface moisture resistance is usually determined by empirical equations like Jürges' (Jürges, 1924) and sometimes even neglected. However, cloth or paper is so thin that the surface resistance has to be determined with a high degree of precision. Although the surface moisture transfer resistance can be made small by setting the wind velocity around the cloth high, the influence of the advection on the resistance of the specimen itself might become significant due to the air permeating the cloth. Thus in measuring the moisture conductivity of clothing materials, the ambient wind velocity should be set as low as possible.

The combined moisture resistance (or wet thermal resistance) of clothing and the air layer between skin and clothing, similar to the concept of clo value as thermal resistance, has been investigated in a number of previous studies of the clothed human body (Woodcock, 1962, Nishi et al., 1970, Mochida et al., 1977, Holmér et al., 1981, Farnworth, 1986, Havenith 

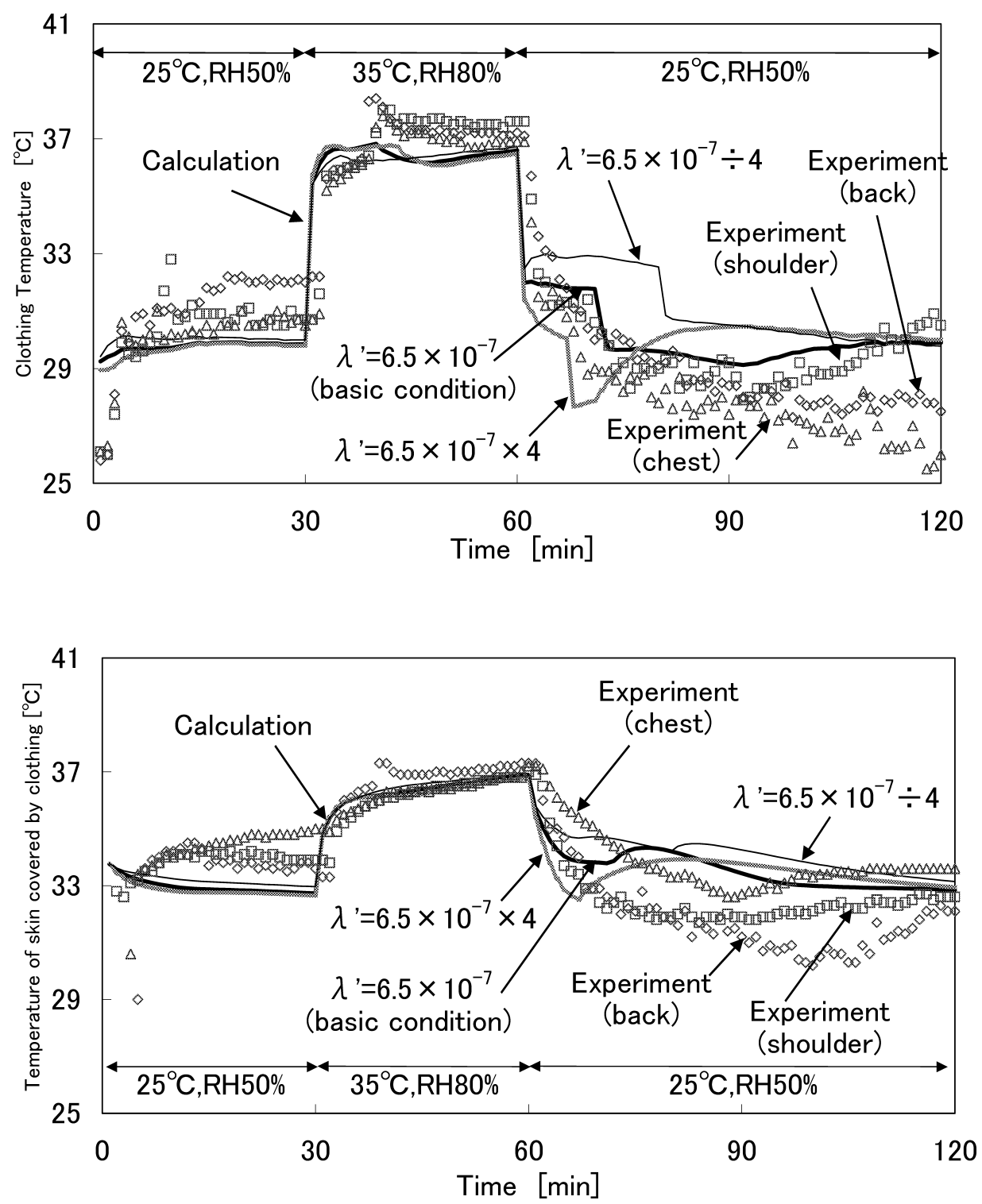

Figures 1 and 2. Sensitivity of moisture conductivity $\left(\lambda^{\prime}\right)$ of clothing (calculated) plotted with the results of experiment in which a male subject wearing T-shirt and trunks transfers between two chambers Top: Clothing temperatures, Bottom: Temperatures of skin covered by clothing.

et al., 1990, Havenith et al., 2002). McCullough et al. (1989) have developed a database of the combined moisture transfer resistance for various kinds of clothing ensembles. Wilson et al. (2000) have investigated the relationship between the combined moisture resistance and the thickness of the cloth. Based on the concept of combined moisture resistance the application to various temperature conditions is difficult and it is hard to take into account the effects of body shape. The volume of the micro environment in clothing has been studied experimentally by Sullivan et al. (1987) and that in bedding items by Holland et al. (1999). Umeno et al. (2001) suggested that the heat and moisture transfer resistance between skin and clothing varies during sweating and its evaporation processes. Therefore, to predict heat and mois- ture transfer around the human body, clothing moisture resistance should be measured as a physical property, separated from the resistances of the layers of air at both surfaces of the clothing. In the field of textile research, Wehner et al. (1988) measured moisture transfer through clothing materials. However, the values of vapor pressure on both sides of the clothing were not shown, and moisture resistance as a material property cannot be determined from their measurements. Nakanishi et al. (1995) measured the moisture conductivity of cloth for 30 kinds of samples. However, in their method, wet filter paper was used to form the wet side boundary and it is difficult to check the humidity at the surface of the filter paper. This study proposes another method based on the wet cup method. 


\section{Method}

As shown in Figure 3, the open top of a plastic box $(8.5 \mathrm{~cm} \times 5.5 \mathrm{~cm} \times 1.4 \mathrm{~cm})$ filled with water was completely covered with the specimen. The specimen frame was fixed tightly to the water box to avoid any air leakage from the sides. The whole experimental set-up in Figure 3 was put on an electronic scale in a climate chamber to control the ambient air temperature at $24^{\circ} \mathrm{C}$. Seven controlled levels of humidity were set, ranging from 30 to $83 \% \mathrm{rh}$, in order to investigate the influence of humidity on moisture conductivity. In general, moisture conductivity is not constant but varies with the moisture content of the material. This dependence of moisture conductivity on moisture content is found in many measurements made of porous building materials (International Energy Agency, 1996). This dependency has not been studied for clothing.

The schematics of the moisture resistance around the specimen are shown in Figure 4. In the experiment, the total resistance $\left(R_{t}^{\prime}\right)$, the surface resistance $\left(R_{s}^{\prime}\right)$ and the air layer resistance $\left(R_{a}^{\prime}\right)$ were determined directly or indirectly from the measured data. The relationship between these resistances is shown in Equation (1). The resistance of the cloth $\left(R_{c}^{\prime}\right)$ and the thickness $\left(L_{c}\right)$ give the moisture conductivity of the cloth $\left(\lambda_{c}^{\prime}\right)$ as shown in Equation (2).

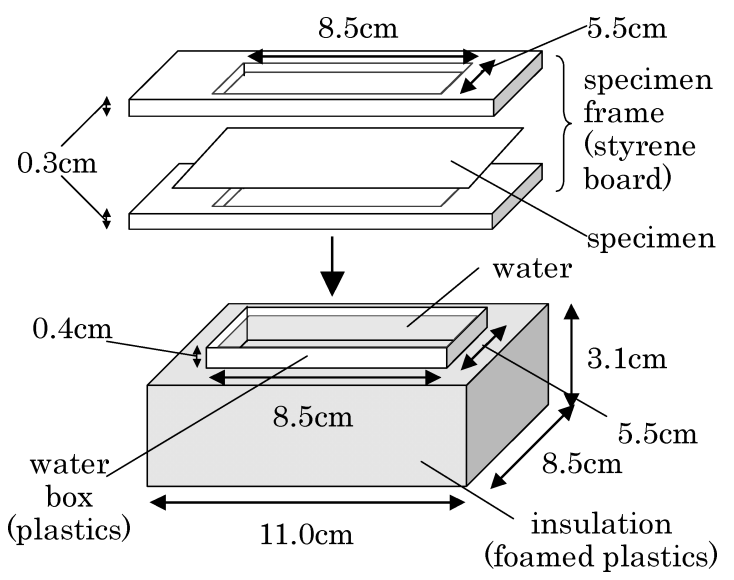

Figure 3. Experimental set up

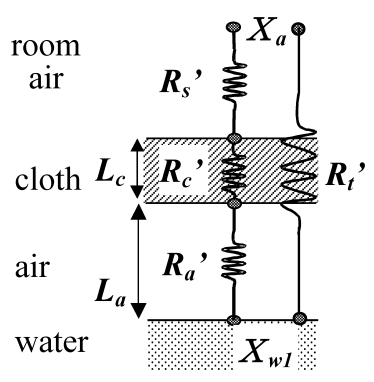

(a)

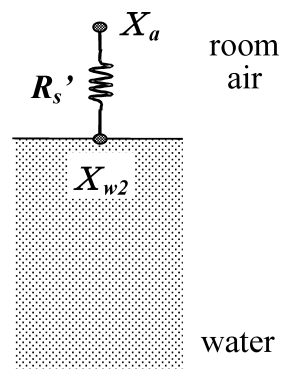

(b)
Figure 4. Schematics of moisture resistance

$$
\begin{aligned}
& R_{c}^{\prime}=R_{t}^{\prime}-R_{s}^{\prime}-R_{a}^{\prime} \\
& \lambda_{c}^{\prime}=L_{c} / R_{c}^{\prime}
\end{aligned}
$$

$R_{t}^{\prime}$ was measured with the specimen frame attached to the water box as shown in Figure 4 (a) and described as follows;

$$
R_{t}^{\prime}=\left(X_{w 1}-X_{a}\right) / E
$$

$X_{w 1}$ was determined from the saturated humidity ratio associated with the water surface temperature $T_{w 1}$. It was determined by measuring the temperature at the bottom of the water box.

$R_{s}^{\prime}$ was measured in an experiment with the same apparatus. This time the water box was filled without the specimen frame as shown in Figure 4 (b).

$$
R_{s}^{\prime}=\left(X_{w 2}-X_{a}\right) / E
$$

Here, it was assumed that the moisture transfer resistance at the surface of the clothing was the same as that of the water surface. The validity of this assumption should be checked in further investigations into the micro structure of the surface.

In determining $R_{a}^{\prime}$, it was assumed that moisture transfer between the water surface and the clothing was described by moisture diffusion in stagnant air. Under this assumption, $R_{a}^{\prime}$ is expressed using the moisture conductivity of stagnant air.

$$
R_{a}^{\prime}=L_{a} / \lambda_{a}^{\prime}
$$

$L_{a}$ is known by the weight change rate of the whole apparatus and the size of the water box. The moisture conductivity of stagnant air $\lambda_{a}^{\prime}$ is given as $2.97 \times 10^{-5}$ $\left[\mathrm{kg} /\left\{\mathrm{ms}\left(\mathrm{kg} / \mathrm{kg}^{\prime}\right)\right\}\right]$, a mean value of the range shown in literature $\left(2.54 \times 10^{-5}\right.$ to $\left.3.39 \times 10^{-5}\right)$ (Bäcktröm et al., 1957).

In order to avoid any air exchange between the air layer under the specimen and ambient air, and to keep the air between the water and the specimen stagnant, the wind velocity around the specimen was kept as low as possible. Each measurement continued for more than 60 hours. Throughout, measurements were recorded of the weight, the temperature at the bottom of the water box, and the temperature and humidity of the ambient air. In order to avoid the influence of any initial temperature change, only the data after 4 hours from setting up were analyzed. The specimen was a sheet of cotton cloth cut from a jersey undershirt, and was $0.4 \mathrm{~mm}$ thick.

\section{Results}

The surface moisture resistance $R_{s}^{\prime}$ was determined from the evaporation measurement without the specimen frame as shown in Figure 4 (b). The result is shown in Figure 5. The measurement of weight was 


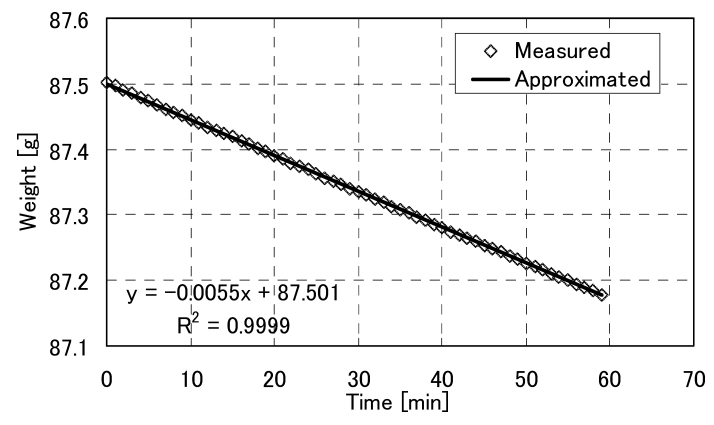

Figure 5. Total weight with time (Evaporation from water surface)

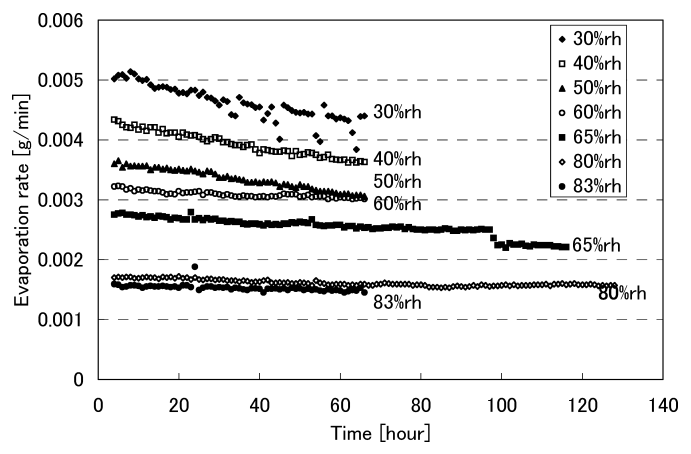

Figure 6. Evaporation rate with time (Legend: humidity of ambient air)

started after the temperature of the water in the box became constant (after the whole apparatus had been exposed to the environment for 2 hours). The weight decreased linearly. By the method of least squares The surface resistance was found to be 290.812 $\left[\left\{\mathrm{m}^{2} \mathrm{~s}\left(\mathrm{~kg} / \mathrm{kg} \mathrm{g}^{\prime}\right)\right\} / \mathrm{kg}\right]$. Based on the Lewis relation, this value is associated with a convective heat transfer coefficient of $3.4\left[\mathrm{~W} /\left(\mathrm{m}^{2} \mathrm{~K}\right)\right]$. Since the wind velocity above the specimen was less than $0.05 \mathrm{~m} / \mathrm{s}$ as measured by a hot-wire anemometer, the value of the resistance seems reasonable.

Next, the specimen frame (Figure 3) was attached to the water box and the weight change was measured. The evaporation rate is shown in Figure 6. For each humidity condition, the evaporation rate becomes smaller as the air layer between the water and the specimen becomes thicker. The water surface humidity ratio $X_{w 1}$ was determined from the saturated humidity ratio associated with the measured temperature shown in Figure 7. The total moisture resistance $R_{t}^{\prime}$ was obtained as seen in Figure 8. Using the values of $R_{s}^{\prime}$ and $R_{a}^{\prime}, R_{c}^{\prime}$ was derived as shown in Figures 9 and 10 .

The values of moisture conductivity are almost constant in low humidity conditions, and increase when the ambient air humidity is 50 to $60 \%$ rh. This suggests that moisture conductivity may depend to some extent on the moisture content of the material. Shown in Figure 9, the values become more widely

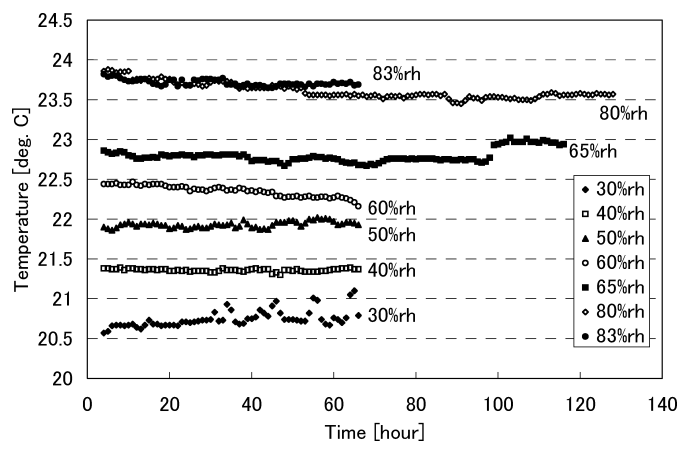

Figure 7. Temperature between bottom of water box and insulation (Legend: humidity of ambient air)

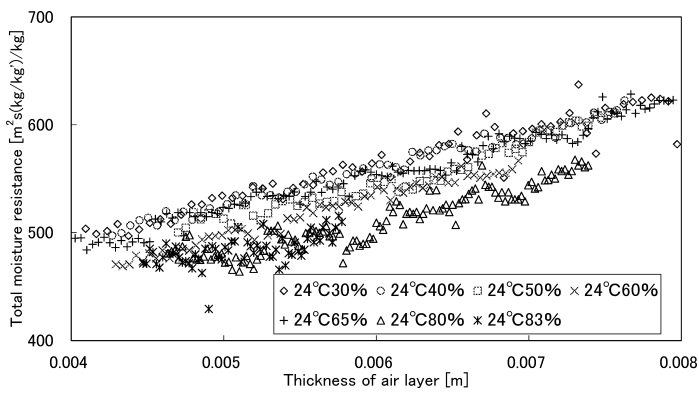

Figure 8. Total moisture resistance $\left(R_{t}^{\prime}\right)$ with thickness of air layer $\left(L_{a}\right)$ (Legend: humidity of the ambient air)

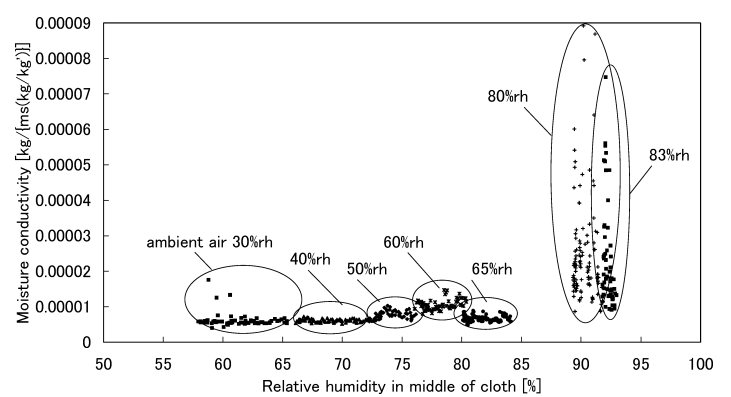

Figure 9. Moisture conductivity $\left(\lambda_{c}^{\prime}\right)$ with humidity in middle of cloth (The humidity in the middle of the cloth was calculated by using the resistance results. The ambient air humidity is also shown.)

distributed as the humidity rises. Shown in Figure 10, some of the data obtained in ambient air conditions of 80 or $83 \%$ rh assume extremely large or small (even minus) values. (In Figure 9, minus values were omitted.) This is because there is a significantly increased likelihood of errors in measurement in higher humidity condition, where the humidity gradient between the water surface and the ambient air is smaller. Figure 11 shows the comparison between moisture resistances. Moisture conductivity is associated with $R_{c}^{\prime}$ and $R_{c}^{\prime}$ is derived by subtracting $R_{s}^{\prime}$ and $R_{a}^{\prime}$ from the total of the three resistances. Under high humidity condition, $R_{c}^{\prime}$ occupies a small fraction of the total, and so accuracy in each of the measured elements becomes critical. Although improvements are 


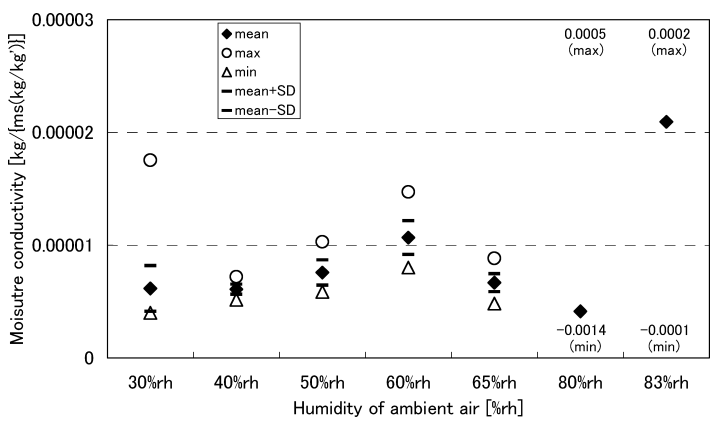

Figure 10. Averaged moisture conductivity $\left(\lambda_{c}^{\prime}\right)$ with humidity of ambient air

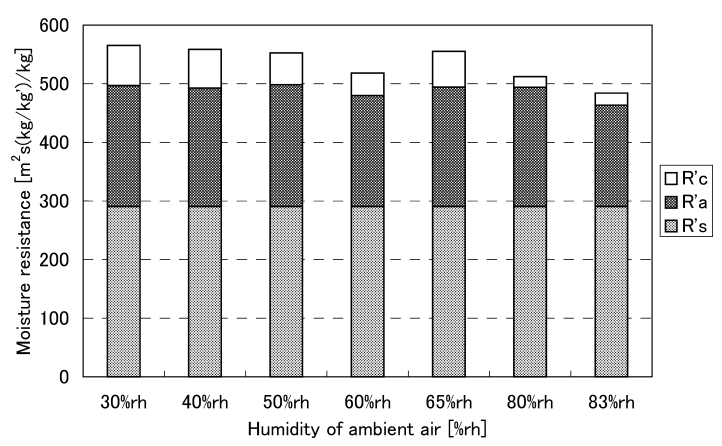

Figure 11. Averaged moisture resistance with humidity of ambient air

necessary for the measurement of higher humidity conditions, this method should still give proper moisture conductivities.

\section{Discussions}

\subsection{Assumption on moisture transfer in air layer}

In this method the moisture transfer in the air layer between the water surface and the specimen ( 3 to 5 $\mathrm{mm}$ ) was assumed to be the moisture diffusion in stagnant air. Here, the validity of this assumption is investigated.

If $\lambda_{c}^{\prime}\left(R_{c}^{\prime}\right)$ can be regarded as constant, the increase in $R_{t}^{\prime}$ should only be due to the increase in $R_{a}^{\prime}$ and the rate is constant.

$$
\frac{d R_{t}^{\prime}}{d L_{a}}=\frac{d R_{a}^{\prime}}{d L_{a}}=k \text { (const.) }
$$

When the thickness of the air layer between the water surface and the clothing is zero, $R_{a}^{\prime}$ is also zero. Therefore,

$$
R_{a}^{\prime}=k \cdot L_{a}
$$

and thus,

$$
\lambda_{a}^{\prime}=L_{a} / R_{a}^{\prime}=1 / k
$$

Here the data from an experiment in which the ambient humidity was controlled at $30 \%$ rh are studied. The relationship between the total moisture resistance $\left(R_{t}^{\prime}\right)$ and the thickness of the air layer $\left(L_{a}\right)$ is shown in

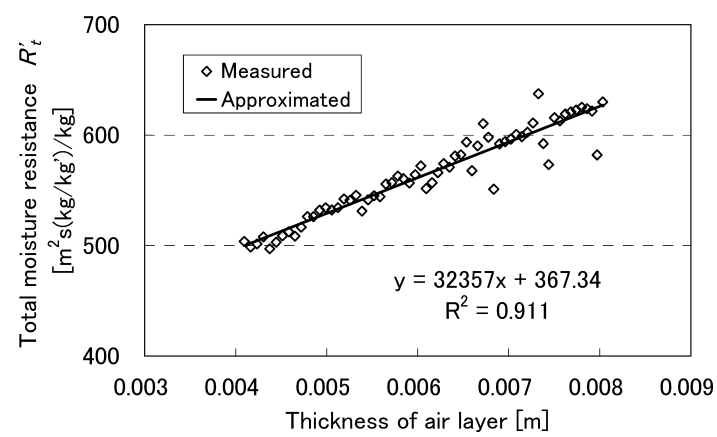

Figure 12. Total moisture resistance $\left(R_{t}^{\prime}\right)$ with thickness of air layer $\left(L_{a}\right)$

\begin{tabular}{|c|c|}
\hline$R_{s}^{\prime}$ & $220\left[\mathrm{~m}^{2} \mathrm{~s}\left(\mathrm{~kg} / \mathrm{kg}^{\prime}\right) / \mathrm{kg}\right]$ \\
\hline$\lambda_{c}^{\prime}$ & $1.0 \times 10^{-5} \quad\left[\mathrm{~kg} /\left\{\mathrm{ms}\left(\mathrm{kg} / \mathrm{kg}^{\prime}\right)\right\}\right]$ \\
\hline$\lambda_{a}^{\prime}$ & $3.0 \times 10^{-5} \quad\left[\mathrm{~kg} /\left\{\mathrm{ms}\left(\mathrm{kg} / \mathrm{kg}^{\prime}\right)\right\}\right]$ \\
\hline$X_{w 1}-X_{a}$ & $0.0062\left[\mathrm{~kg} / \mathrm{kg}^{\prime}\right]$ \\
\hline
\end{tabular}

Table 1. Calculation conditions in checking influence of moisture capacity of cloth

Figure 12. A good linear fitting is obtained. At the same time, from the gradient of the linear regression line $(k)$, the moisture conductivity of the air layer $\left(\lambda_{a}^{\prime}\right)$ is found to be $3.07 \times 10^{-5}\left[\mathrm{~kg} /\left\{\mathrm{ms}\left(\mathrm{kg} / \mathrm{kg}^{\prime}\right)\right\}\right]$. This value is within the range of values in the literature $2.54 \times 10^{-5}$ to $3.39 \times 10^{-5}$ (Bäcktröm et al., 1957). This supports the assumption.

\subsection{Temperature at water surface}

The vapor pressure at the water surface depends on the temperature. However, it is difficult to measure this directly while measuring moisture conductivity. In this method, the temperature at the bottom of the water box was measured instead of the surface temperature. The distance between the surface and the bottom is 7 to $9 \mathrm{~mm}$, and the temperature difference between them would be no more than $0.2^{\circ} \mathrm{C}$, according to a heat transfer calculation in the non-steady state using the experimental results on evaporation rate. Therefore, this way of determining the vapor pressure at the water surface is acceptable.

\subsection{Influence of moisture capacity}

The moisture flux from the water to the ambient air should be constant in the cup method. However, a steady state is not established at any time in a strict sense because of the continuous change in the thickness of the air layer between the water and the specimen. Thus it is necessary to check the influence of non-steady behavior of the moisture in the clothing, namely the influence of the moisture capacity of the cloth. Here a simple numerical example is investigated, using the conditions in Table 1. 
When the thickness of the air layer is 4.0 and $4.1 \mathrm{~mm}$, the moisture flux in the steady state should be $1.576 \times 10^{-5}$ and $1.563 \times 10^{-5}\left[\mathrm{~kg} / \mathrm{m}^{2} \mathrm{~s}\right]$, respectively. Now, if the thickness of the air layer changed from 4.0 to $4.1 \mathrm{~mm}$ discontinuously, the moisture flux would change from $1.576 \times 10^{-5}$ to $1.563 \times 10^{-5}$ $\left[\mathrm{kg} / \mathrm{m}^{2} \mathrm{~s}\right]$ without considering the moisture capacity of the cloth. On the other hand, when the moisture capacity is taken into account, the moisture flux just after the change would be $1.576 \times 10^{-5}\left[\mathrm{~kg} / \mathrm{m}^{2} \mathrm{~s}\right]$ at most. The difference between the two cases is only $0.82 \%$. The change is actually continuous so the influence of the moisture capacity should be much smaller. Thus it can be concluded that the non-steady behavior of the cloth is not significant in this method.

\section{Conclusions}

A method to measure the moisture (water vapor) conductivity of clothing was proposed in this paper. The difficulty in applying the wet cup method to cloth was overcome by determining the surface moisture transfer resistances at both sides of cloth gravimetrically. For a cotton cloth specimen, the moisture conductivity was measured, and at the same time, the surface resistances on both sides of the cloth specimen were determined. It was shown that improved measurements are needed in conditions of high humidity and that the moisture conductivity is affected by humidity.

\section{Nomenclature \\ $E: \quad$ Evaporation rate $\left[\mathrm{kg} /\left(\mathrm{m}^{2} \cdot \mathrm{s}\right)\right]$ \\ $L:$ Thickness [m] \\ $T:$ Temperature $\left[{ }^{\circ} \mathrm{C}\right]$ \\ $R^{\prime}$ : Moisture transfer resistance $\left[\mathrm{m}^{2} \cdot \mathrm{s} \cdot\left(\mathrm{kg} / \mathrm{kg}^{\prime}\right) / \mathrm{kg}\right]$}

$X$ : Humidity ratio $\left[\mathrm{kg} / \mathrm{kg}^{\prime}\right]$ (Mass of moisture per unit mass of dry air in a moist air mixture)

$\lambda^{\prime}: \quad$ Moisture conductivity $\left[\mathrm{kg} /\left\{\mathrm{m} \cdot \mathrm{s} \cdot\left(\mathrm{kg} / \mathrm{kg}^{\prime}\right)\right\}\right]$

\section{Suffix}

a: Ambient air

c: Cloth (specimen)

w1: Surface of the water covered by cloth specimen shown in Figure 4 (a)

w2: Surface of the water shown in Figure 4 (b)

\section{References}

Bäcktröm, M., Emblik, E. (1957) Kältetechnik. G. Braun: 423.

Farnworth, B. (1986) A numerical model of the combined diffusion of heat and water vapor through clothing. Textile Research Journal 56: 653-665.

Havenith, G., Heus, R., Lotens, W. A. (1990) Clothing ventilation, vapour resistance and permeability index: changes due to posture, movement and wind. Ergonom- ics 33 (8): 989-1005.

Havenith, G., Holmér, I., Parsons, K. (2002) Personal factors in thermal comfort assessment: clothing properties and metabolic heat production. Energy and Buildings 34: 581-591.

Holland, E. J, Wilson, C. A., Laing, R. M., Niven, B. E. (1999) Microclimate ventilation of infant bedding. International Journal of Clothing Science and Technology 11 (4): 226-239.

Holmér, I. and Elnäs, S. (1981) Physiological evaluation of the resistance to evaporative heat transfer by clothing. Ergonomics 24 (1): 63-74.

International Energy Agency (1996) Energy Conservation in Buildings and Community Systems IEA ANNEX 24 Heat, Air and Moisture Transfer Through New and Retrofitted Insulated Envelope Parts (Hamtie) Final Report Volume 3 Task 3. Material Properties.

ISO 12572 (2000) Hygrothermal performance of building materials and products-Determination of water vapour transmission properties. Geneva, ISO.

Jürges, I. W. (1924) Der Warmeubergang an einer ebenen Wand. München and Berlin, Druck und Verlag von R. Oldenbourg.

McCullough, E. A., Jones, B. W. and Tamura, T. (1989) A Data Base for Determining the Evaporative Resistance of Clothing. ASHRAE Transactions 95 (2): 316-328.

Mochida, T., Yokoyama, S. (1977) Moisture permeation efficiency of clothing. Transactions of SHASE of Japan 3: 79-87.

Nakanishi, M. Niwa, M. (1995) An Analysis of the Steady State Heat and Moisture Transfer through Clothing Materials (Part 2) Heat Transfer with Perspiration. Journal of Home Economics of Japan 46 (6): 567-575.

Nishi, Y., Gagge, A. P. (1970) Moisture permeation of clothing - a factor governing thermal equilibrium and comfort. ASHRAE Transactions 76: 137-145.

Sullivan, P. J., Mekjavic, I. B., Kakitsuba, N. (1987) Determination of clothing microenvironment volume. Ergonomics 30 (7): 1043-1052.

Takada, S., Hokoi, S., Kawakami, N., Kudo, M. (2001) Thermophysiological response of human body in nonsteady state considering influence of transfer and storage of heat and moisture in and around clothing-Subject experiment and analysis by two-node model. Journal of architecture, planning and environmental engineering 549: 23-30.

Umeno, T., Hokoi, S., Takada, S. (2001) Transient Thermal Response of Human Body Considering Moisture Accumulation in Clothing. ASHRAE Transactions 107 (1): 4418.

Wehner, J. A., Miller, B., Rebenfeld, L. (1988) Dynamics of water vapor transmission through fabric barriers. Textile Research Journal: 581-592.

Wilson, C. A., Laing, R. M., Niven B. E. (2000) Multiplelayer bedding materials and the effect of air spaces on 'wet' thermal resistance of dry materials. Journal of Human-Environment System 4 (1): 23-32.

Woodcock, A. H. (1962) Moisture transfer in textile systems Part I. Textile Research Journal: 628-633. 